\title{
Does gymnasium harbor an endemic cause of end stage kidney disease? a case report \& review of literature
}

\begin{abstract}
Gymnasium is an English word describing a place for physical training and simply referred to as Gym. Nowadays, in Gym physical training is associated with consumption of high protein and non-protein supplements aiming to have effective muscle and bone building in short time. Those supplements accompanied with strenuous exercise and dehydration results in high incidence of acute kidney injury. We report a 26-year-old male, casual bodybuilder, giving positive history of anabolic steroids intake, creatine supplements consumption, high protein diet, and using energy drinks for rehydration, Accidentally discovered to have end stage kidney disease, His Urine analysis was unremarkable, His Renal ultrasound showed grade III hyper-echogenicity and his Renal biopsy revealed severe renal cortical damage, glomerulosclerosis percentage was $100 \%$, IFTA percentage was $90 \%$, non-specific C3 staining of one glomerulus, Electron microscopy was not conclusive as all glomeruli were sclerotic in the specimen. In conclusion, Gym nephropathy is multifactorial and can be prevented by spreading the knowledge of healthy eating, good hydration during training and unleash the dangers of high protein and non-protein supplements for bodybuilding.
\end{abstract}

Keywords: creatine, acute intestinal nephritis, acute renal failure, chronic renal failure, high protein diet, branched chain AA, energy drinks
Volume 7 Issue 3 - 2019

\author{
Ahmed AKL, ${ }^{1,2,3}$ Yasser Aldabbagh' \\ 'Dr Soliman Fakeeh Hospital, KSA \\ ${ }^{2}$ Associate professor, Fakeeh College medical sciences, KSA \\ ${ }^{3}$ Urology \& Nephrology Center, Mansoura University, Egypt \\ Correspondence: Ahmed AKL, Associate Professor, Fakeeh \\ College Medical Sciences, Jeddah, KSA Consultant Nephrology \\ \& Transplantation, DR. Soliman Fakeeh Hospital, Jeddah, \\ KSA, Consultant Nephrology \& Transplantation, Urology \& \\ Nephrology Center, Mansoura University, Egypt, \\ Email aiak1200I@yahoo.com
}

Received: May 06, 2019 | Published: July 10, 2019

\section{Introduction}

Gymnasium is the Latin word for old Greek word gymnasion which means a place where young men practice physical \& intellectual activities. It is a place of intellectual activities which can be found in European languages. In contrary, Gymnasium in English language is defined as being a place for physical activities only and shortened to the form "Gym". Nowadays, in Gym, athelets beside the practice of physical activity, they frequently consume non hormonal and hormonal supplements in order to acquire a muscle bulk and strength in a short time. ${ }^{1}$ The main non-hormonal supplements include proteins, creatine and vitamins, and the hormonal supplements are the anabolic steroids. ${ }^{2}$ Recently reported in literature that 10 body builders suffered chronic kidney disease due to focal segmental glomerulosclerosis (FSGS) after consuming large amounts of anabolic steroids with high protein daily intake of 300-550 g/day. ${ }^{3}$ The high-protein intake carries a lot of concern because it increases glomerular filtration rates and proved experimentally to be associated with glomerular hyper filtration ending with FSGS. ${ }^{2}$ Furthermore, pure creatine powder is marketed as a muscle building supplement. It is safe \& effectively contributing to exercise tolerance and improve muscle strength. ${ }^{4,5}$ Creatine is widely used by casual and professional athletes. ${ }^{6}$ The reported adverse events is usually because of the exercise-induced rhabdomyolysis and dehydration leading to acute kidney injury. However, many cases report un-linking creatine-associated acute kidney injury to rhabdomyolysis. ${ }^{8-11} \mathrm{~A}$ one report describing a body builder suffered from acute tubular necrosis after taking a high dose up to $20 \mathrm{~g}$ /day for a week. ${ }^{9}$ Another report, describing acute intestinal nephritis in two body builders. ${ }^{10,11}$

Sports dieticians sometimes recommend higher doses of vitamin D over the recommended daily allowances (RDA) to strength bone building. ${ }^{12,13}$ A sustained ingestion of over $50000 \mathrm{IU}$ a day can cause hypercalcemia with the potential for metastatic renal calcification. ${ }^{12}$ Vitamin D toxicity, usually seen in hospitalized infants as a result of over dose, but considered minimal and rarely seen in adults in normal situations. ${ }^{13,14}$ Anabolic androgen steroids (AAS) proved to be directly toxic to podocytes through stimulation of podocyte androgen receptors leading to podocyte loss and segmental sclerosis. ${ }^{15}$ In addition, AAS side effects includes an increase in the risk to have coronary attack, acute myocardial infarction, cholestatic jaundice, transaminitis, rhabdomyolysis plus severe mood and psychotic disorders. ${ }^{16}$ Herein, we report our case to alert nephrologists and general physicians to bodybuilders behaviors and their trainers that may place young men at risk for new era of kidney injury we named gym nephropathy.

\section{Case report}

A 26-year-old male, active bodybuilder, accidently discovered low hemoglobin level when he was donating blood, his $\mathrm{HB}$ was $8 \mathrm{~g} / \mathrm{dl}$ and serum creatinine $12 \mathrm{mg} / \mathrm{dl}$, BUN $118 \mathrm{mg} / \mathrm{dl}$ and metabolic acidosis PH 7.2, and serum bicarbonate was $14 \mathrm{mmol} / 1$. No previous medical history, his sister known to have systemic lupus (SLE). Renal us done and revealed average size kidneys $8 \times 5 \mathrm{~cm}$ with grade III hyperechogenicity, urine analysis was unremarkable, Patient gave positive history of anabolic steroids intake, creatine supplements consumption, high protein diet, and he was using energy drinks for rehydration. Immunological work up including anti-neutrophilic antigen (ANA), C3, C4, ESR, CRP all came normal. Renal biopsy included up to 19 glomeruli, all of them globally sclerosed. Tubular atrophy and interstitial scarring affect about $90 \%$ of the cortical area. Surviving proximal tubular epithelium shows cytoplasmic protein reabsorption droplets and hypertrophic changes focally. Five small arteries are included that show fibro-intimal thickening. Thrombotic microangiopathy is not seen Figure 1(A) \& Figure (B). Immunofluorescence Microscopy showed sections stained for Albumin, Fibrinogen, C1q, C3, IgG, IgM, 
IgA, Kappa light chain \& Lambda light chain. There is positivity for C3 $(3+)$ in sclerosed glomeruli. Traces of mesangial IgM are seen in sclerosed glomeruli. Other immune-stains are negative except for IgA positivity of hyaline casts and positivity for IgM, IgA, Kappa and lambda chains in atrophic tubular basement membranes Figure 1(C). Electron microscopy was not conclusive as all glomeruli were sclerotic in the specimen [Biopsy pathology processing and analysis was done at Express Med laboratories, Kingdom of Bahrain]. He received normal strength saline (77 meq sodium bicarbonate in oneliter $1 / 2 \mathrm{NSS}$ ) at rate of $2 \mathrm{ml} / \mathrm{kg} / \mathrm{hour}$, urine output was satisfactory
1300-1600 ml/day. After two days of IV fluids serum creatinine showed partial improvement from 12 to $10 \mathrm{mg} / \mathrm{dl}$ and BUN 118 to $98 \mathrm{mg} / \mathrm{dl}$. In view of the partial improvement of kidney function and possibility of patchy kidney sclerosis, we started the patient on low dose oral steroid dose with monitoring of kidney function. After two weeks, no response to steroids was observed, patient was declared to have end stage renal disease (ESRD) and prepared to initiate regular hemodialysis and kidney transplantation option was discussed with the patient.

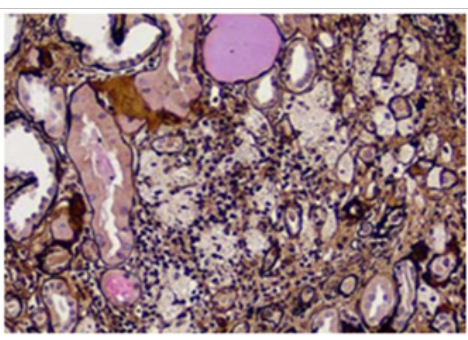

(A)

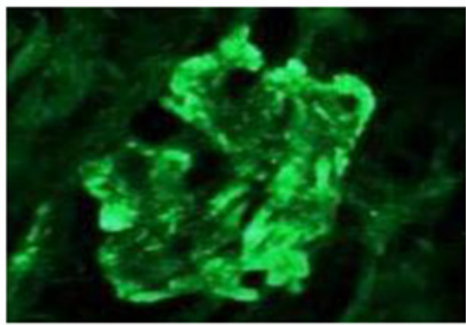

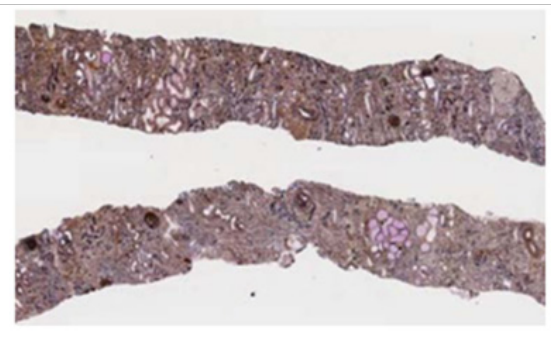

(B)

(C)

Figure I Histopathology of core needle renal biopsy.

Figure I: shows (A, B) Light Microscopy: severe chronic renal parenchymatous damage, glomerulosclerosis I00\%; IFTA $90 \%$. (C) Immunofluorescent microscopy: There is positivity for $\mathrm{C} 3(3+)$ in sclerosed glomeruli. Traces of mesangial lgM are seen in sclerosed glomeruli. Other immunostains are negative except for lgA positivity of hyaline casts and positivity for IgM, IgA, Kappa and lambda chains in atrophic tubular basement membranes.

\section{Discussion}

Creatine supplement increases creatine storage and promotes a rapid regeneration of adenosine triphosphate in-between extensive exercises. Nowadays, its use is increasingly observed among Gym athletes. Studies have shown that protein supplement, when it is used in doses more than recommended, it could be associated with acute tubular necrosis or acute intestinal nephritis and tend to resolve with stopping of protein supplements. ${ }^{3-4}$ Our patient was not following the dose recommended by his coach as he was taking triple the prescribed creatine and protein supplements. A significant chronicity was found in renal biopsies of patients on maintenance protein supplements. However, it is difficult to rule out a pre-existing chronic kidney disease that may be associated with supplements use. ${ }^{5}$ Our patient family history was positive for systemic lupus nephritis but all the immunological screening were negative. Many reports correlating the incidence of acute kidney injuries in Gym trainees to consumption of anabolic steroids with moderately high amounts of commercial nutritional supplements containing protein \& creatine in doses exceeding the allowed recommended dose on a continuous basis. Published renal biopsies demonstrated acute tubular injury, and when the anabolic steroids \& protein supplement utilization stopped early, kidney function improved within 4 weeks.
This raised the concern of the association between high protein supplement use and ESRD. A number of Gym trainees suffered hypercalcemia, ESRD with nephrocalcinosis while consuming vitamin D with estimated doses of $>10$ million IU annually. This finding raised the possibility of vitamin D toxicity induced nephrocalcinosis encountered in four Brazilian Gym trainees. ${ }^{17-19}$ The nephrocalcinosis was described to be due to the silicon-like effect of oily carrying medium that was added to vit $\mathrm{D}$ injections that was used to increase specific muscle groups bulk. ${ }^{17-19}$ Vitamin D toxicity is the milk- or calcium alkali syndrome. ${ }^{20-22}$ An excessive consumption of milk or anti-acid calcium carbonate compounds leads to this syndrome. Nowadays, the calcium-alkali syndrome is seen in post-menopausal women receiving supplemental calcium \& vitamin D for osteoporosis. Among our patient, milk \& calcium consumption could not be considered greatly excessive. Acute phosphate nephropathy with intratubular calcium phosphate deposition was reported in subjects receiving oral sodium phosphates used for bowel preparation before colonoscopy. ${ }^{23}$ Protein powder contains little inorganic phosphate with three daily supplement servings providing $<0.5$ g. ${ }^{24}$ Creatine is sold mainly in the form of a monohydrate also with little phosphorus. Daily 2-3 Liters of milk consumption will add 1.6-2.4 g to a normal dietary phosphorus intake of $1.0-1.5 \mathrm{~g}^{24}$ This is well below the $11 \mathrm{~g}$ oral intake used in bowel preparations. ${ }^{23}$ 
For most Gym trainees, sports dieticians recommend a daily protein intake of $1.4-1.7 \mathrm{~g} / \mathrm{kg} / \mathrm{day}^{2,25}$ There is substantial experimental and clinical data supporting the safety of creatine supplementation when it is used in the recommended amounts, but there is concern that excess dietary protein and creatine that is not accompanied by increased fluid intake may lead to a relative hypovolemia. ${ }^{5-8}$ In reported cases of acute kidney injury in creatine users; one demonstrated acute tubular necrosis, but two were classified as acute interstitial nephritis suggesting idiosyncratic allergic reactions. ${ }^{9-11}$ We must emphasize that a specific offending agent cannot be identified in our case, and it may be the combination of excess creatine, protein with anabolic steroids injections that compounds risk not incurred with the individual substances. In conclusion: we encourage youth to practice a healthy lifestyle and sports. We are presenting this case to focus on a serious and hidden cause of end stage renal disease emerging in young population due to consumption of high protein supplements, anabolic steroids and creatine during practicing sports in gym. This danger can be prevented through acknowledgement of a public alert program.

\section{Ethical standards}

The present study was performed in accordance with the ethical standards of the institutional research committee and with the Helsinki declaration.

\section{Informed consent}

Written consent was obtained from the patient discussed and documentation is available for review upon request.

\section{Acknowledgments}

None.

\section{Conflicts of interest}

Authors declare No conflict of interest.

\section{References}

1. Fink HH, Burgoon LA, Mikesky ARE. Practical Applications in Sports Nutrition. $2^{\text {nd }}$ edn. Sudbury, MA: Jones and Bartlett, 2009. p. 220-254.

2. Martin WF, Armstrong LE, Rodriguez NR. Dietary protein intake and renal function. Nutr Metab. 2005;2:25.

3. Herlitz LC, Markowitz GS, Farris AB, et al. Development of focal segmental glomerulosclerosis after anabolic steroid abuse. J Am Soc Nephrol. 2010;21(1):163-172.

4. Engelhardt M, Neumann G, Berbalk A, et al. Creatine supplementation in endurance sports. Med Sci Sports Exerc. 1998;30(7):1123-1129.

5. Deldicque L, Décombaz J, Zbinden FH, et al. Kinetics of creatine ingested as a food ingredient. Eur J App Physiol. 2007;102(2):133-143.

6. Cooper R, Naclerio F, Allgrove J, et al. Creatine supplementation with specific view to exercise/sports performance: an update. J Int Soc Sports Nutr. 2012;9(1):33.
7. Sandhu RS, Como JJ, Scalea TS, et al. Renal failure and exercise-induced rhabdomyolysis in patients taking performance-enhancing compounds. $J$ Trauma. 2002;53(4):761-763.

8. Yoshima WM, Tsourounis C. Effects of creatine supplementation on renal function. J Herb Pharmacother. 2004;4(1):1-7.

9. Taner B, Aysim O, Abdulkadir U. The effects of the recommended dose of creatine monohydrate on kidney function. NDT Plus. 2011;4(1):23-24.

10. Thorsteinsdottir B, Grande JP, Garovic VD. Acute renal failure in a young weight lifter taking multiple food supplements. J Ren Nutr. 2006;16(4):341-345.

11. Koshy KM, Griswold E, Schneeberger EE. Interstitial nephritis in a patient taking creatine. $N$ Engl J Med. 1999;340:815-815.

12. Hathcock JN, Shao A, Vieth R, et al. Risk assessment for vitamin D. Am J Clin Nutr. 2007;85(1):6-18.

13. OM (Institute of Medicine). Dietary Reference Intakes for Calcium and Vitamin D. Washington, DC: The National Academies Press, 2011

14. Jones G. Pharmacokinetics of vitamin D toxicity. Am J Clin Nutr. 2008;88:582S-586S

15. Pendergraft WF III, Herlitz LC, Thornley-Brown D, et al. Nephrotoxic effects of common and emerging drugs. Clin J Am Soc Nephrol. 2014;9(11):1996-2005.

16. Hartung R, Gerth J, Fünfstück R, et al. End-stage renal disease in a bodybuilder: a multifactorial process or simply doping? Nephrol Dial Transplant. 2001;16(1):163-165.

17. Daher EF, Silva Júnior GB, Queiroz AL, et al. Acute kidney injury due to anabolic steroid and vitamin supplement abuse: report of two cases and a literature review. Int Urol Nephrol. 2009;4(1):717-723.

18. Rocha PN, Santos CS, Avila MO, et al. Hypercalcemia and acute kidney injury caused by abuse of a parenteral veterinary compound containing vitamins A, D, and E. J Bras Nefrol. 2011;33(4):467-471.

19. Rocha PN, Santos CS, Avila MO, et al. Hypercalcemia and acute kidney injury caused by abuse of a parenteral veterinary compound containing vitamins A, D, and E. J Bras Nefrol. 2011;33(4):467-471.

20. Beall DP, Henslee HB, Webb HR, et al. Milk-alkali syndrome: a historical review and description of the modern version of the syndrome. Am J Med Sci. 2006;331(5):233-242.

21. Patel AM, Goldfarb S. Got calcium? Welcome to the calciumalkali syndrome. J Am Soc Nephrol. 2010;21(9):1440-1443.

22. Khan SR. Nephrocalcinosis in animal models with and without stones Urol Res. 2010;38(6):429-438.

23. Heher EC, Thier SO, Rennke H, et al. Adverse renal and metabolic effects associated with oral sodium phosphate bowel preparation. Clin J Am Soc Nephrol. 2008;3(5):1494-1503.

24. Gaucheron FG. The minerals of milk. Review Reprod Nutr Dev. $2005 ; 45(4): 473-483$.

25. Tarnopolsky M. Protein and amino acid needs for training and bulking up In: Burke L, et al., editors. Clinical Sports Nutrition, $3^{\text {rd }}$ edn. McGraw Hill Australia Pty Ltd, 2006. p. 73-103. 